DOI: 10.20472/IAC.2019.049.038

\author{
ANIKÓ TOMPOS \\ Széchenyi István University, Győr, Hungary
}

\title{
INTERNATIONAL STUDENTS AT A YOUNG HUNGARIAN UNIVERSITY: MOTIVATIONS AND CHALLENGES
}

\begin{abstract}
:
Recent years have seen increased efforts of Hungarian tertiary educational institutions to internationalise their educational activities. As well as the expected enhancement of academic reputation and the generation of income, these activities are triggered by governmental policies and strategies, namely the expectations towards a substantial rise in the ratio of international students at Hungarian institutions of higher education. Internationalisation is supported by the expansion of scholarship programmes available for foreign students, for example the Stipendium Hungaricum Programme, which was brought to life by a government decree in 2013 and amended in 2015. The aim of the study reported in the paper is to explore the motivations of Stipendium Hungaricum scholarship holders studying at the University of Győr (Széchenyi István University), Hungary as well as the challenges they face in an academic environment more often than not quite different from that in their home countries. The paper first briefly introduces the programme and overviews the results of Hungarian nationwide surveys on foreign students in general and Stipendium Hungaricum scholarship holders in particular. Then it moves on to discuss the findings of structured interviews carried out among master- and bachelor-level full-time Stipendium Hungaricum scholarship students at the University of Györ. The discussion focuses on three topics: (1) What motivated these students to apply for a relatively young rural university rather than more established rural universities or those located in the capital? (2) What aspects of instruction do they consider different from those in their home institutions? (3) What are their plans after graduation? The findings are believed to contribute to the better understanding of cross-cultural differences as well as to the creation of more effective international promotional campaigns.
\end{abstract}

\section{Keywords:}

internationalisation of higher education, student motivations, challenges

JEL Classification: $121,123,128$ 


\section{Introduction}

Recent years have seen increased efforts of Hungarian tertiary educational institutions to internationalise their educational activities. These efforts are in line with the social, educational and training policy of the European Union, which aims to build a more cohesive European society and further, conform to the demands of the European labour market, which, in order to be more competitive, needs a larger pool of competent labourers (Lannert, 2018).

In Hungary, internationalisation of higher education is supported by the expansion of scholarship programmes available for foreign students, for example the Stipendium Hungaricum Programme. The programme is intended to support economic policy goals as well as to stimulate quality development in Hungarian tertiary education.

The aim of the study reported in the paper is to explore the motivations of Stipendium Hungaricum scholarship holders studying at the University of Győr (Széchenyi István University), Hungary as well as the challenges they face in an academic environment more often than not quite different from that in their home countries. The paper first briefly introduces the programme and overviews the results of Hungarian nationwide surveys on foreign students in general and Stipendium Hungaricum scholarship holders in particular. Then it moves on to discuss the findings of structured interviews carried out among master- and bachelor-level full-time Stipendium Hungaricum scholarship students at the University of Györ. The discussion focuses on three topics: (1) What motivated these students to apply for a relatively young rural university rather than more established rural universities or those located in the capital? (2) What aspects of instruction do they consider different from those in their home institutions? (3) What are their plans after graduation? The findings are believed to contribute to the better understanding of cross-cultural differences as well as to the creation of more effective international promotional campaigns.

\section{The Stipendium Hungaricum Programme}

The Stipendium Hungaricum Programme was brought to life by a government decree in 2013 and amended in 2015. As an educational policy, it has a threefold purpose: (1) to promote the quality improvement of Hungarian higher education by supporting internationalisation processes; (2) to strengthen academics' international relations through the increase in cultural diversity and (3) to promote a more competitive Hungarian higher education. It follows, that "the scholarship not only aims to increase the number of incoming students, but also to intensify higher education cooperation with international partner organisations" (Kasza and Hangyál, 2018, p. 10). Tempus Public Foundation, which was established as early as in 1996 and operates under the supervision of the Ministry of Human Resources, plays an important role in the coordination of the programme. 
At present nearly 70 sending partners participate in the scholarship programme from five continents. The number of students taking part in the programme is steadily increasing: while there were only 47 Stipendium Hungaricum scholarship holders in 2013, their number rose to 5148 in 2017 (Kasza and Hangyál 2018). Since 2015 there have been scholarship holders studying in degree programmes conducted in Hungarian, but their number is quite low (393 students in 2017). In $201791 \%$ of the degree programmes were in English, however, six other languages (French, German, Italian, Russian, Spanish and Swedish) were also available (https://tka.hu/palyazatok/7619/statisztikak).

A study surveyed the opinions of 1566 full-time and part-time international tertiary students with 1269 respondents being Stipendium Hungaricum holders (Malota, 2016). The results of the survey show that the three most frequently mentioned reasons to study in Hungary were (1) high quality education; (2) the wish to get familiar with another culture and (3) affordable prices, while the most important information sources to help make the decision were internet scholarship portals and information received from friends. Among the respondents, Stipendium Hungaricum students were the most satisfied with the quality of education, infrastructure and the help received from the administrative staff (support in general orientation) of institutions of higher education. The study concluded that "students perceive Hungary as an ideal educational destination by a higher probability if they are satisfied with the following: academic programme, teaching methods, use of online tools on the courses, scientific prestige, relationship with other students, helpfulness of the tandem/buddy/mentor student, sport facilities (at the university), computer facilities (at the university), satisfaction with the rented flat, accommodation facilities (in the city), regularity of the payment of the scholarship" (Malota, 2016, p. 5).

The survey carried out next year with the participation of 2825 Stipendium Hungaricum holders gave very much the same results regarding the motivations of foreign students to study in Hungary. International students in 2017 attributed an even higher importance to the three above-mentioned factors: "The quality of the education is high" (2016: 49\%; 2107: 51\%); "I wanted to get to know another culture" (2016: 40\%; 2017: 46\%); "It is a financially affordable country" (2016: $36 \%$; $2017: 38 \%$ ) followed by "The country has a good reputation" (2016: 23\%; 2017: 26\%), while the remaining thirteen motivational factors (university partnership, unique academic programme, recommendation, having friends or relations in Hungary) were attributed much lower significance (Kasza and Hangyál, 2018). Still another factor in the survey was "It is the country where I would like to develop my future career". Only $16 \%$ of the Stipendium Hungaricum respondents claimed they wanted to stay and work in Hungary (2016: 17\%). Like in 2016, students were satisfied with factors related to the quality of education. On a 1-5 scale all the means exceeded the middle point with "usage of internet and online tools in courses" (4.08) and "support and advice you have received from your professors/lecturers/teachers" (4.02) receiving the highest 
ratings and "teaching methods your professors/lecturers/teachers use in your courses" (3.8) and "English knowledge of your professors/lecturers/teachers" (3.8) receiving the lowest ones (Kasza and Hangyál, 2018).

In 2017 a total of 415 training programmes were offered to Stipendium Hungaricum scholarship applicants. Most of the degree programmes (65) were offered by the University of Debrecen, Eötvös Loránd University, Budapest (58) and the University of Pécs (53). 168 training programmes were offered by institutions located in Budapest, the Hungarian capital, and well-established rural tertiary educational institutions based in Debrecen (64), Pécs (53) and Szeged (37) accounted for $42.4 \%$ of the degree programmes for the scholarship holders (Kasza and Hangyál, 2018). In the autumn semester of the academic year of $2017 / 18$ there were a total of 73 Stipendium Hungaricum scholarship students in three faculties of the author's institution, Széchenyi István University located in Györ, in the north-west of Hungary (https://tka.hu/palyazatok/7619/statisztikak).

The University of Györ is a young university, established only fifty years ago as a College of Transport and Telecommunications. However, now it includes, as a faculty, the former Teacher Training College, which has a history of 240 years. The university's strategy puts a strong emphasis on the stimulation and support of internationalisation since it intends to triple the number of full time degree programmes at bachelor, master and doctoral level in the academic year of 2019/2020 (https://admissions.sze.hu/-study). To this end, efforts have been made to renew and expand the institutional infrastructure as well as to improve the linguistic and methodological competences of the academic and administrational staff (AblonczyMihályka 2018).

\section{Purpose and method}

The present study aims to answer the following three research questions:

(1) What motivated Stipendium Hungaricum scholarship holders studying at the University of Györ to apply for a relatively young rural university rather than more established rural universities or those located in the capital?

(2) What aspects of instruction do they consider different from those in their home institutions?

(3) What are their plans after graduation?

The ultimate aim of the small-scale qualitative research described below is to gain useful pieces of information which can be utilised when designing and monitoring the internationalisation of Széchenyi István University's academic activities. 
Structured interviews with 10 Marketing MA Stipendium Hungaricum students in the first and second years of their studies and 8 International Relations BA Stipendium Hungaricum students, also in the first and second years of their studies were carried out to answer the research questions. These numbers account for about 50 percent of the respective students in both courses. The English-language Marketing MA full degree programme was introduced at the University of Györ in 2014 as one of the first two master-level programmes while the English-language International Relations BA was launched in 2017 as the first bachelor-level full degree programme of the institution.

The interviews were conducted in the spring semester of the academic year 2018/19. As well as demography-related questions and those referring to previous studies abroad, the interviews touched upon other issues, for example why respondents chose Hungary, general impressions about the Hungarian culture as well as positive and negative critical interactional incidents in everyday situations and students' interpretations of these incidents, however, the discussion of these topics falls out of the scope of the present study. The interviews were recorded and transcribed.

It should be noted that the Marketing MA course is only offered to Stipendium Hungaricum applicants only at two institutitons: Corvinus University in Budapest and the University of Györ, while the International Relations BA course is offered by a total of five institutions, the other four being Corvinus University in Budapest, Eötvös Lóránt University in Budapest, the University of Pécs and the University of Kaposvár. Another important piece of information is that the programme allows students to transfer from one institution to another.

\section{Results}

The discussion below summarises the results concerning the three research questions. In general, information received from master-level students was more detailed than that gained from bachelor-level respondents.

\subsection{Why the University of Györ?}

Students' answers in general touched upon two aspects: in the first place the city itself and then attractive qualities associated with the university.

Most students (16) mentioned the favourable location of the city. Indeed Györ is of almost equal distance $(80-120 \mathrm{kms})$ from three capitals: Vienna (Austria), Bratislava (Slovakia) and Budapest (Hungary). The other most often-highlighted aspect was that the city is not too big (at present it has about 130.000 inhabitants) - the phrases students used comprised "cosy", "easy to navigate", "peaceful and quiet enough for 
studying and living". Other aspects included the fact that Györ is one of most developed cities in Hungary and it looks "nice".

In fact, the city seems to have affected Marketing MSc students' choices since - as stated above - there are only two universities offering this training to Stipendium Hungaricum applicans; the other university is based in Budapest, the capital, which has about two million inhabitants.

As far as the university itself is concerned, most respondents (12) emphasised the academic reputation of the institution. Next came the contents of the study programmes (curriculum) and the conviction that the university seemed international student-friendly. Other aspects included the campus and the student hostels. One MSc student referred to the promotional video of the university, another one to a friend, who recommended the institution to him, while a BA student said she had read good reviews about the university.

Below are some responses to the question "Why did you choose Széchenyi István University".

The campus life, the dorms and the facilities that the university offers to the students. Because of the curriculum, and attractive facilities and surroundings of university.

Academically highly ranked university, ultimate college vibe: the campus location combines the resources of a cosmopolitan city with the charm of the city of Györ, a beautiful campus, the people and above all I felt it was the right thing to do, compared to universities in the capital and where I transferred from.

I did not choose specifically Széchenyi István University; I was searching for any university that can offer me the bachelor course for International Relations in English. After I found this university, I concluded that it is a good option, because the town in which it is situated is not too big, and is also halfway between Vienna and Budapest. I was also pleased to find some good reviews about this University as well, and it seemed to be international student-friendly.

\subsection{In what way is instruction different?}

Interviewees answered two questions to shed light on this aspect:

(1) What are your general impressions about the institutional culture of Széchenyi István University?

(2) Can you recall and describe a concrete incident that took place during your stay (time, scene, setting, participants, what happened, positive or negative experience, your feelings/reaction, etc.) in an academic setting (with Hungarian peers, lecturers, stuff, etc.)? 
Answers were quite diverse and culture-dependent. A number of respondents mentioned the relationship between students and lecturers. However, some of them felt it was too formal, whereas others thought it was friendly:

The relationship between teachers and students is very formal, meanwhile in my country we are very close to our teachers where sometimes we go out with them and eat with them. Even though there is still the respect of the teacher still exists but also the good and friendly relationship is also there.

From my point of view, it should be the gap between teacher and student compare to my country we are pretty close. We respect each other like relative or parent and children.

Compared with Chinese power distance in the institutional culture, it is lower. Professors or lecturers are more modest and would like to chat or discuss with students. Students have more opportunities of voicing their own points of view. Unlike China with the culture of high power distance, the voice of people with lower social status or younger age is usually ignored. In the meanwhile, comparatively speaking, it tends to be participate style in leadership. In that way, the opinions of each member are taken into consideration to make the final decision.

Interviewees in general seem to be happy with the lecturers and staff as well as other international and Hungarian students, however, there was one MSc student who expressed a contradictory opinion.

Greeting, when we meet each other whether it be in campus, dormitory and so on they will say hi to me even if I am a stranger to them.

The institutional culture of Széchenyi István University is mainly students' need oriented. The administration tries to provide the best conditions for each student to get better knowledge base for the future carrier. Some weeks ago, a Hungarian student approached to me to ask me some questions about my culture and country. She made deep research about my country in advance. I spent time to answer all her question with detailed answers taking a cup of coffee. I would do the same thing now because I think I should reward all those people who are interested in my culture. Sometimes I feel that I am ambassador of my culture.

For what I see something similar to any other school, but I think that it lacks actions to include international students, I understand that we are here as foreigners and maybe we should be the ones trying to blend in, but still I feel that sometimes we are totally aliens in this school.

Academic regulations also provoked positive and negative remarks. For example, a Pakistani student expressed the view that having the opportunity to take an exam four 
times "just mars the motivation of a student and this way students do not take it seriously", whereas a Laotian student said, "I am impressed with the exam system at this university because it gave me opportunity to retake exams while the system in my bachelor degree university is different. I could have only one chance, if I failed the exam, I had to retake the course again in the next semester. I view that student life should not be over-pressured by the examination". A Turkish student was also of the opinion that it is beneficial for students to have several options if they are not satisfied with their grades and further, he said he liked the idea of pre-examinations, which allow for less intensive examination periods.

Further critical remarks included the obligatory use of pens in examinations, the lack of official lunch time and lecturers' acceptance of students eating and drinking during classes. These came from MSc students, who almost exclusively have 4-lesson blocks in the same subject in their timetable. At the same time, a Kenyan student praised the flexibility of the institution, since it allows students to take subjects from other bachelor-level programmes (but on completion of these courses they do not get credits /ECTs) and that students can simultaneously take part in two full degree programmes:

I would highly recommend the institutional culture of Széchenyi István University, especially at the subject program. A culture which can offer a student an opportunity to choose subjects from other programmes and study simultaneously two undergraduate programmes. This is a unique culture that needs to be cultivated and given priority not only by Széchenyi István University but by the Hungarian Government.

\subsection{Plans after graduation}

Two interview questions aimed to find out how students felt about Hungary in general and the University of Györ in particular and whether they intend to stay in Hungary or pursue further studies at the university:

(1) Are you enjoying your stay in Hungary? Are you planning to stay after your graduation?

(2) Are you happy with Széchenyi István University? Are you planning to conduct master (and maybe doctoral) studies / doctoral studies here or at another Hungarian University?

All respondents said they were happy with Hungary. Seven MSc and four BA students stated they would like to stay here after the completion of their degree, for shorter or longer periods. However, almost all of them said they would have to evaluate their possibilities.

Yes, I'm enjoying my time here, yes I'm planning to stay two years after my graduation and after this I will change. 
It depends on the opportunities I have here and there - whatever is better for me and my career and life in general I would go for. But I don't have any problem with staying here.

Yes, I am enjoying my stay in Hungary, however I am not planning to stay after my graduation, unless offered a chance to do so. Why not?

Yes, I am enjoying my stay in Hungary and I am also trying to learn Hungarian. If I can find a good job opportunity in Hungary, I am thinking to stay after my graduation.

I'm really happy and I started to feel that this is my second family, and I want to learn the Hungarian language so I can start a life in here after my finishing the master degree hopefully.

It should be noted that at present in Hungary there are limited job opportunities for people who do not speak Hungarian, at least in rural areas. In fact, many international students would like to do part-time or occasional work during or between semesters to supplement their scholarship payment, yet only a few succeed in finding jobs in and around Györ.

Most respondents (16) claimed they were happy with the University of Györ (Széchenyi István University; SZE in short). Five MSc students and three BA students said they would like to step up to master/doctoral-level education in this institution, whereas one BA student stated (s)he wanted to find another university in Hungary. However, almost all of them pointed out they would only continue their studies if they were provided another scholarship. Three MSc students stated they do not plan to take part in any $\mathrm{PhD}$ programme.

Yes, I am glad to be here and planning to study in doctoral education. So I see opportunities related to future.

Yes, I'm happy and I really like it. Yes, I'm planning to have a PhD and my first choice again will be SZE university. I would really be happy to be accepted for a PhD.

Yes, I am happy with this university since its accommodation condition and teaching conditions are better than some universities in Budapest. If there is a chance I can get to further doctoral studies, I would like to stay at our university, Széchenyi István University.

Until now, I am happy to be one of the SZE's student and l'd like to keep being still its student. On the other hand, I also would like to get new experiences, new challenges. So it's all about opportunities. 
Yes, I am happy with Széchenyi István University. I would be happy to conduct my master degree here, if there would be provided the scholarship for the International Relation course.

Given the opportunity I can spent my life time in this university: masters, doctoral degrees. The chances of getting a consecutive nomination for a scholarship are very low. But if I fall in that 1\% nominated I will choose SZE over and over again.

\section{Conclusions}

The above-discussed smale-scale research aimed to gain useful pieces of information to be utilised when planning and monitoring the internationalisation of Széchenyi István University's academic activities. These small pieces of information might be important since the image of a tertiary educational institution is shaped by the information coming from foreign students who have studied or are studying at the given institution; their opinion affects the institution's attractiveness and reputation and moreover, the future of its internationalisation efforts (Szöke, Ablonczy-Mihályka and Tompos, 2017).

Results gained from answers to the first research question indicate that the university's promotion should focus on the attractive qualities of the city where it is located as well as those of the institution itself. Respondents emphasised the favourable location of the Györ, and also that it is nice, not too big and well-developed. The phrases they used ("cosy", "easy to navigate", "peaceful and quiet enough for studying and living") can be utilised in promotional campaigns. As far as the university itself is concerned, interviewees highlighted its academic reputation, the content of the degree programmes, the international student-friendly atmosphere, the location of the campus as well as life on the campus (events) and the quality of the student hostels. These again allow for inclusion into the promotional brochures and video. Certainly, as the answers indicate, as well as the marketing campaigns, students' choices are affected by information gained from friends and reviews written by international students.

Respondents' often controversial opinions on the characteristics of the academic instruction underlines the need for intercultural trainings so that lecturers are aware of cross-cultural differences and prepared to handle different student expectations. At the same time, international students, at the very beginning of their studies, need to be made familiar with the institutional educational regulations, which conform to national regulations, for example with the system of pre-examinations and the possible number of exam resits. The orientation week before the first semester and the mentor system (international students have student and lecturer mentors; the former are individual mentors, the latter degree programme mentors) allow for students' familiarisation with 
the regulations as well as the practicalities, for example the obligatory use of pens at examinations and the lack of official lunch breaks.

As mentioned in the literature review, in the 2017 nationwide survey $16 \%$ of the Stipendium Hungaricum respondents claimed they wanted to stay and work in Hungary. The present small-scale investigation showed higher willingness to stay for higher-level studies, however, most students said they would need another scholarship to step up to master or doctoral level. As for working in Hungary, no BA student expressed the wish to find a job here, while in the case of MSc students the number was three. The language barrier, as pointed out above might contribute to this result. Steps have already been made to solve this problem, since the university offers optional Hungarian language courses to international students and further, the subject called Hungarian language and culture will be a compulsory component of each English-language study programme from the autumn semester of the academic year 2019/2020.

\section{Acknowledgement}

The author would like to acknowledge the project EFOP-3.6.1-16-2016-00017 Internationalisation, initiatives to establish a new source of researchers and graduates, and development of knowledge and technological transfer as instruments of intelligent specialisations at Széchenyi István University for its financial support.

\section{References}

ABLONCZY-MIHÁLYKA, L. (2018). Dialogue of cultures in higher education. In: ROTSCHEDL, J. and CERMAKOVA, K. (eds.) Proceedings of the 43rd International Academic Conference, Lisbon. Prague: International Institute of Social and Economic Sciences (IISES), International Society for Academic Studies. pp. 2-10.

KASZA, G. and HAGYÁL, ZS. (2018). Stipendium Hungaricum Scholarship Holders' Expectations and Attitudes. Budapest: Tempus Public Foundation.

LANNERT, J. (2018). International Students in Hungarian Higher Education Institutions. Executive Summary. Budapest: Tempus Public Foundation.

MALOTA, E. (2016) Student Satisfaction Survey 2016. Hungary and Hungarian higher education according to international students. Budapest: Tempus Public Foundation.

SZÖKE, J., TOMPOS, A. and ABLONCZY-MIHÁLYKA, L. (2017). Internationalisation and intercultural competence in the context of tertiary education. In ŠTEFANČíK, R. and KAPIL, R. (eds.) Cudzie jazyky v premenách času VII. / Foreign Languages in Changing Times VII. Recenzovanỳ zborník prívspevkov z mezdinárodnej vedeckej konferencie / Reviewed Conference Proceedings from an International Scientific Conference. Bratislava: Vydavatel'stvo EKONÓM. pp. 123-127. 
https://admissions.sze.hu/-study

https://tka.hu/palyazatok/7619/statisztikak 